\title{
Endoscopic treatment of gastric varices bleeding with the use of n-butyl-2 cyanoacrylate
}

\author{
Sławomir Kozieł, Konrad Kobryń, Rafał Paluszkiewicz, Marek Krawczyk, Tadeusz Wróblewski \\ Department of General, Transplant and Liver Surgery, Medical University of Warsaw, Warsaw, Poland
}

Prz Gastroenterol 2015; 10 (4): 239-243

DOI: $10.5114 /$ pg.2015.56112

Key words: gastrointestinal bleeding, gastric varices, portal hypertension, tissue glue, endoscopy.

Address for correspondence: Sławomir Kozieł MD, Department of General, Transplant and Liver Surgery, Medical University of Warsaw, 1a Banacha St, 02-097 Warsaw, Poland, phone: +48 2259925 45, e-mail: chirurg9@poczta.onet.pl

\begin{abstract}
Introduction: Oesophageal varices and gastric varices are naturally-formed, pathological portosystemic shunts that occur in patients with portal hypertension. Gastric varices are responsible for about $10 \%$ of variceal bleeding; however, they are also the cause of massive haemorrhage, often with dramatic progress.

Aim: To assess the results of endoscopic treatment of gastrointestinal bleeding from oesophageal and gastric varices using tissue glue Histoacryl.

Material and methods: From January 2013 to May 2015170 patients underwent a total of 244 obliterations with the administration of tissue glue due to gastroesophageal varices. We analysed 35 patients who received urgent endoscopic intervention due to life-threatening gastric variceal bleeding.

Results: Thirty-five patients underwent 47 endoscopic procedures of haemorrhage management. Immediate haemostasis was achieved in 32 (91.4\%) patients. In 3 (8.6\%) cases endoscopy failed. In 2 patients a Linton tube was applied before secondary endoscopy. A single trans jugular portosystemic shunt (TIPS) was performed. Permanent haemostasis during the first endoscopy was achieved in $26(74 \%)$ patients. Six (17\%) patients presented recurrent bleeding 1-4 days following the initial treatment. Three patients had a splenic artery embolisation performed. One of the embolised patients required surgery, and a splenectomy was carried out.

Conclusions: If this kind of therapy is unavailable at the time, it is advised that one of the conventional methods of controlling bleeding is used, introducing basic life support and transporting the patient to a specialist centre with adequate endoscopic facilities, radiological possibilities of endovascular intervention, and surgical treatment of liver transplantation.
\end{abstract}

\section{Introduction}

Oesophageal varices (EV) and gastric varices (GV) are naturally-formed, pathological portosystemic shunts that occur in patients with portal hypertension $(\mathrm{PH})$. Portal blood pressure exceeding $10 \mathrm{~mm} \mathrm{Hg}$ leads to the formation of collateral circulation through the left gastric vein (LGV), posterior gastric vein (PGV), short gastric veins (SGV), and left and right gastroepiploic veins to the submucosal veins of the stomach and the oesophagus, leading to the formation of varices. It is clear that oesophageal varices occur in $50 \%$ and gastric varices in approx. $20 \%$ of liver cirrhotic patients. In nearly $10 \%$ of cases gastric varices coexist with those of the oesophagus. Thus, when mentioning varices associated with $\mathrm{PH}$, we must distinguish their three groups: oesophageal varices, gastroesophageal varices (GOV), and isolat- ed gastric varices (IGV). There are many classifications drawn up describing oesophageal varices. The most popular one in Poland is the four-degree OMED scale, which determines the degree of variceal enlargement in relation to the oesophageal wall. Gastroesophageal varices are typically divided into two groups: GOV1 are oesophageal varices extending to the lesser curvature of the stomach; and GOV2 are oesophageal varices that extend in the direction of the fundus and its greater curvature. Isolated gastric varices are divided into IGV1 - varices of the fundus, and IGV2 - varices localised in other parts of the stomach and duodenum, i.e. antrum, body, or the pylorus itself [1].

Gastric varices are responsible for about $10 \%$ of variceal bleeding; however, they too are the cause of massive haemorrhage, often with dramatic progress. This is due to the high intensity of bleeding, difficul- 
ties of identifying the location of the haemorrhage in a stomach filled with blood clots, and limited methods of treatment. The risk of bleeding depends on the size and location of varices. Approximately $70 \%$ of GV are GOV1, but they are the cause of haemorrhage in only $11 \%$ of cases. However, IGV1 comprises of a mere $8 \%$ of gastric varices, but they are responsible for about $80 \%$ of variceal bleeding. It is important to say that isolated gastric varices frequently occur in patients with normal liver function, being the result of portal vein thrombosis or loco-regional portal hypertension caused by thrombosis of the splenic artery (SA) or its anatomical anomalies. For this reason, having treated the bleeding, the prognosis is better than in patients with impaired liver function $[1,2]$.

\section{Aim}

The aim of this study is to assess the results of endoscopic treatment of gastrointestinal bleeding from oesophageal and gastric varices using tissue glue Histoacryl.

\section{Material and methods}

From January 2013 to May 2015170 patients underwent endoscopic treatment at our centre due to gastric varices. A total of 244 varices obliterations with the administration of tissue glue were performed in this group. The procedures were mostly elective treatments within the scope of primary and secondary prevention of bleeding. In this group, 35 patients required urgent endoscopic intervention due to active GV bleeding. In 24 (69\%) cases IGV1 was the source of bleeding, GOV2 was recognized in $10(28 \%)$ patients, and 1 (3\%) patient had bleeding classified as IGV2 located in the pylorus. Among the causes of $\mathrm{PH}$ portal vein thrombosis, liver cirrhosis of different aetiology and a single case of Budd-Chiari syndrome were observed. The exact figures are presented in Table I.

All patients were qualified for urgent endoscopy under general anaesthesia with endotracheal intuba-

Table I. Causes and occurrence of portal hypertension

\begin{tabular}{lcc} 
Causes of portal hypertension & Number & Percent \\
\hline Thrombosis of portal vein trunk & 11 & 31.4 \\
\hline Isolated thrombosis of splenic vein & 8 & 22.9 \\
\hline Alcoholic liver disease-induced cirrhosis & 8 & 22.9 \\
\hline Hepatitis B and C-induced liver cirrhosis & 6 & 17.2 \\
\hline Primary biliary cirrhosis & 1 & 2.8 \\
\hline Budd-Chiari syndrome (BCS) & 1 & 2.8
\end{tabular}

tion. The procedure was performed using Olympus endoscopes with a 3.7-mm biopsy channel incorporating a jet channel for swift and intense irrigation by WaterJet. In the case of massive retention of blood clots in the stomach, which made it impossible to find the source of the bleeding, in order to aspirate the contents a 6- $\mathrm{mm}$ wide channel Olympus endoscope was used. After locating the bleeding site, each of the patients underwent obliteration of varices bleeding with the application of n-butyl-2 cyanoacrylate - an adhesive tissue glue called Histoacry $l^{\circledast}$ manufactured by B. Braun Surgical SA.

The tissue glue used for the treatment of varices is a liquid monomer solution that upon contact with fluid from the serum rapidly polymerises turning into its solid state. With this feature, the glue fills the lumen of the varix, and while flowing out through the rupture, as it turns into its solid state, it seals the opening in the varix causing immediate cessation of bleeding. In order to slow down polymerisation and to allow free injection into the varix, the Histoacryl is diluted by the addition of Lipiodol in a $0.5 \mathrm{ml} / 0.5 \mathrm{ml}$ proportion. Because of the relatively high density of the formula, it is necessary to use large endoscopic needles 21-19 G in diameter for treatment. Following the insertion of the needle into the lumen of the varix, the solution has to be quickly injected, and once the drug is administered the needle should be flushed with $2 \mathrm{ml}$ of $0.9 \%$ saline and retracted into its cover to prevent adhesion to the varix itself. During the treatment of variceal bleeding, the injection should be performed at the apex of the varix, possibly near the site of the rupture and blood outflow. Administration of tissue glue outside the varix, into the intramural layer, can lead to necrosis of the stomach wall, deep ulceration, and perforation. Typically, a single procedure requires 2-10 injections of $1.0 \mathrm{ml}$ each [3]. Images 1-2 present bleeding from a ruptured varix and injection of Histoacryl into the lumen of the varix, which fills the opening and halts the bleeding. Image 3 presents the result three days following the obliteration.

\section{Results}

In the study 35 patients underwent 47 endoscopic procedures of haemorrhage management. Immediate haemostasis was achieved in 32 (91.4\%) patients. In $3(8.6 \%)$ cases endoscopy alone was unsuccessful because bleeding was excessive. In two of them bleeding was effectively controlled with the use of a Linton tube applied for $24 \mathrm{~h}$ and removed the consecutive day prior to a second endoscopic glue obliteration. In one case an urgent transjugular portosystemic shunt (TIPS) was performed. Six patients (17\%) presented recurrent bleeding 1-4 days following the initial treatment. They were managed endoscopically and obliteration was carried 
Table II. Characteristics of variceal treatment

\begin{tabular}{lccc} 
Type of varices & GOV2 & IGV1 & IGV2 \\
\hline No. of patients & 10 & 24 & 1 \\
\hline Definitive haemostasis achieved & 10 & 21 & 1 \\
\hline Recurrent bleeding & 2 & 4 & 0 \\
\hline No. of endoscopic procedures & 15 & 31 & 1 \\
\hline $\begin{array}{l}\text { No. of Histoacryl injections per } \\
\text { procedure }\end{array}$ & $\pm 4(2-6)$ & $\pm 7(4-13)$ & 2 \\
\hline Linton tube application & 0 & 2 & 0 \\
\hline TIPS & 0 & 1 & 0 \\
\hline Embolisation of splenic artery & 1 & 2 & 0 \\
\hline Splenectomy & 0 & 1 & 0 \\
\hline Liver transplantation & 11 & 2 & 0
\end{tabular}

out with good results. Three patients were diagnosed with recurrent bleeding caused by isolated splenic vein thrombosis, which was later treated by interventional radiology, and splenic artery embolisation was performed. One of the embolised patients required surgery, and a splenectomy was carried out. Permanent haemostasis during the first endoscopic treatment was achieved in 26 (74\%) patients. For complete elimination of varices, patients required 1-4 subsequent obliterations within the model of secondary prophylaxis of bleeding. The procedures were performed electively in 3-4-week intervals $[4,5]$. The results are shown in Table II.

In the study 6 incidences of recurrent bleeding were observed as described above. Mortality was $8.6 \%$ due to the death of 3 patients who developed hepatic decompensation and multi-organ failure, which caused

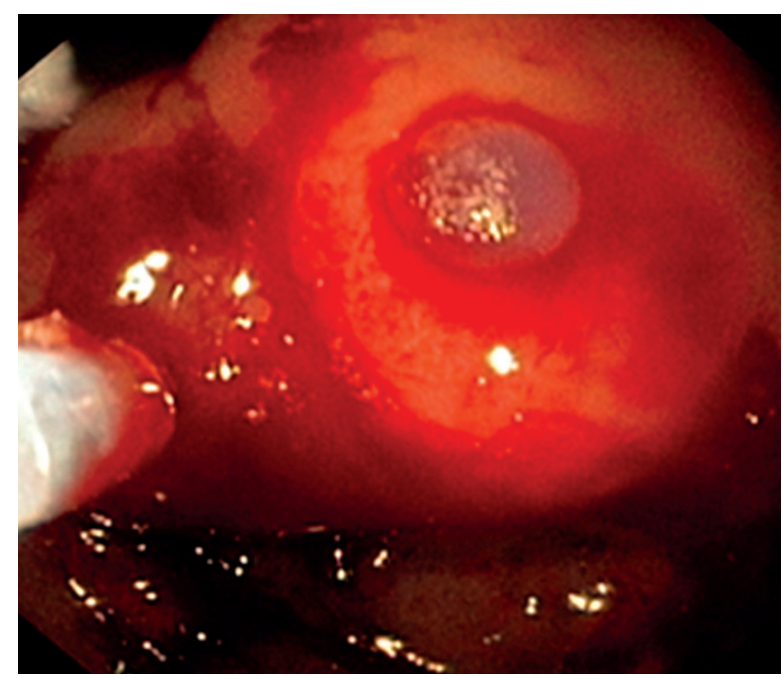

Figure 2. Histoacryl application into lumen of varix

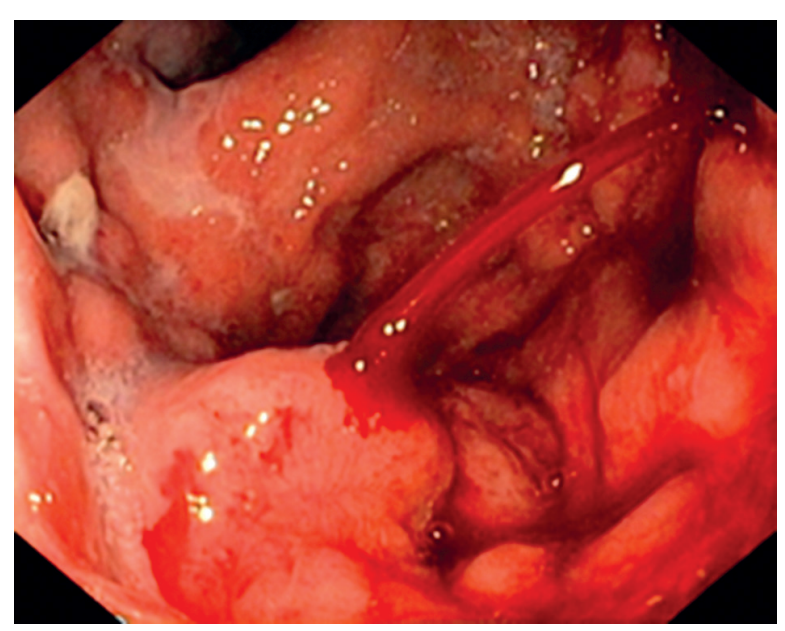

Figure 1. Bleeding gastric varix

massive haemorrhage. Other serious complications, such as perforation and embolic complications, were not observed.

Discomfort and pain was reported in 11 patients, which was successfully managed by administration of analgesics. In 17 patients mild fever was observed. Among the presented group, there were 13 patients with eradicated GOV, who underwent elective liver transplantation with successful results. They currently do not require endoscopic treatment (Figures 1-3).

\section{Discussion}

One of the most serious complications of portal hypertension is GOV bleeding. Mortality during the first variceal haemorrhage reaches $20-30 \%$, and as much as $50 \%$ during the second incidence. Recurrence of bleeding is observed in $30 \%$ of patients within the first

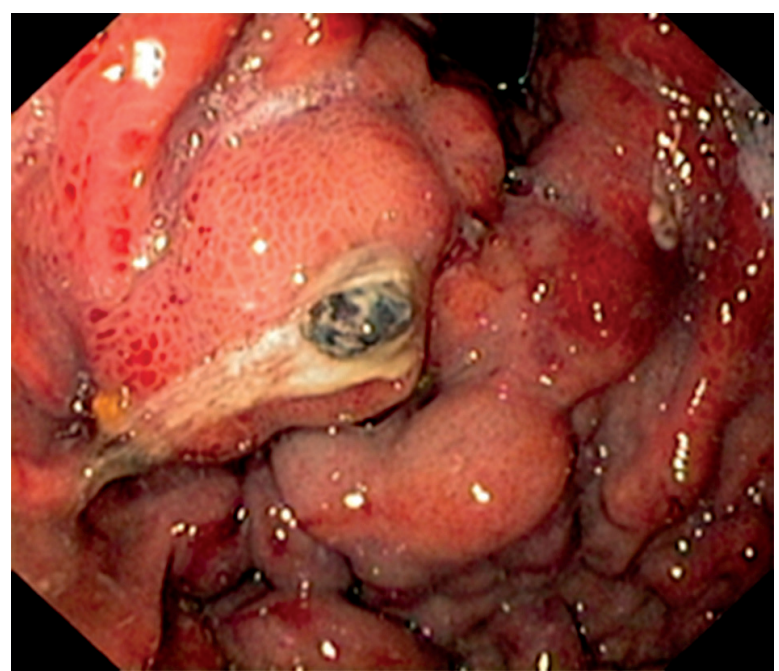

Figure 3. Result of treatment. Image taken 3 days post obliteration 
6 weeks of the first episode and in about 70\% during the following year. The risk of bleeding increases with duration of disease, the degree of liver failure according to Child-Pugh's classification, the size of varices, the presence of signs of threatening and for coming bleeding and hepatic venous pressure gradient (HVPG) $[2,5]$. Patients with haemorrhage from oesophageal and gastric varices are a group of patients at a high risk of mortality. Their treatment is based on intensive resuscitation, pharmacotherapy, and endoscopic surgery. Endoscopic treatment depends on the type of varices and the location of the haemorrhage [4, 6-8]. Endoscopic treatment should be engaged as soon as possible, $12 \mathrm{~h}$ from the onset of symptoms of bleeding at the latest; this is based on the 2010 guidelines from the consensus in Baveno $\mathrm{V}$ [9]. The method of choice in the management of bleeding from oesophageal varices is their ligature by banding endoscopic variceal ligation (EVL). In the absence of such a possibility or technical difficulties sclerotherapy is an accepted alternative form of treatment. Endoscopic tissue glue therapy (N-butyl-2-cyanoacrylate) is recommended in the case of bleeding from isolated gastric varices IGV1 and IGV2 and gastroesophageal varices GOV2 in cases of bleeding from sites located below the cardia. When the cause of haemorrhage is GOV1, use of EVL or tissue adhesive glue is recommended. Please note that the use of adhesives in localised bleeding in the oesophagus should be very cautious and limited to exceptional cases. The tissue glue deposited in the wall of the oesophagus may lead to the development of deep ulceration, and even perforation and embolic complications are more frequent. As a result, it can lead to mediastinitis with the need for oesophageal stenting using coated self-expandable metal stents as a life-saving procedure [10]. There is data describing safe administration of Histoacryl in cases of haemorrhage from duodenal and gastric ulcers when traditional methods of argon beamer coagulation failed to stop the bleeding [11]. Concerning the treatment of gastric varices, elastic banding is not recommended and should not be applied [8]. Massive haemorrhage may recur if the elastic band is loosened too early. Overly aggressive aspiration of the varix may damage and cause perforation to the wall of the stomach. The use of fibrin glue in bleeding from gastric varices is a safe and effective method of treatment with a satisfyingly low rate of adverse events [12-15]. In most cases, the injection of tissue glue to the lumen of the varix allows definite haemostasis to be achieved. In the case of recurrent bleeding, treatment can be repeated. An important factor improving the effectiveness of the procedure is a properly cleansed stomach. Retention of blood clots and debris significantly impedes visibility and delays or prevents the identification of bleeding. The use of wide-channel endoscopes with the irrigation function supplied by jet channels greatly facilitates the washing out of clots and aspiration of all gastric contents. General anaesthesia with endotracheal intubation plays a great role in this procedure. This increases the comfort and safety of the patient, eliminating the possibility of tracheal aspiration of content, and allows us to change the alignment of the body in order to move the contents of the stomach. In cases where endoscopic therapy fails or when, for various reasons, urgent endoscopy cannot be performed, and bleeding persists despite pharmacological treatment, a Sengstaken-Blakemore or Linton tube must be applied. The insertion of the tube is still life saving and gives enough time (up to $24 \mathrm{~h}$ ) for the endoscopic procedure to be carried out or for transfer of the patient to a specialised centre were the treatment is feasible. Dedicated centres with high expertise in the field have a possibility of radiological intervention to carry out splenic artery embolisation or TIPS if necessary $[16,17]$. In certain cases treatment may resolve to splenectomy. Patients with gastric varices, in whom the underlying disease is liver cirrhosis, may be considered for liver transplantation (LTX), thus LTx eliminates portal hypertension and the risk of variceal bleeding.

\section{Conclusions}

Bleeding from gastric varices is a serious but relatively rare complication of portal hypertension. The most appropriate treatment in these cases is endoscopic obliteration of varices by administration of tissue glue. If this kind of therapy is unavailable at the time, it is advised that one of the conventional methods of controlling bleeding is used, introducing basic life support, and transporting the patient to a specialist centre with adequate endoscopic facilities, radiological possibilities of endovascular intervention, and surgical treatment of liver transplantation.

\section{Conflict of interest}

The authors declare no conflict of interest.

\section{References}

1. Sarin SK, Kumar A. Gastric varices: profile, classification and management. Am J Gastroenterol 1989; 84: 1244-9.

2. Sarin SK, Lahoti D, Saxena SP, et al. Prevalence, classification and natural history of gastric varices. Hepatology 1992; 16: 1343-9.

3. Żurakowski J, Wróblewski T, Paluszkiewicz R, et al. Endoskopowe tamowanie krwotoku z żylaków przełyku i żołądka przy użyciu histoakrylu. Videochirurgia 2000; 5: 7-11.

4. Mishra SR, Sharma BC, Kumar A, et al. Primary prophylaxis of gastric variceal bleeding comparing cyanoacrylate injection 
and beta-blockers: a randomized controlled trial. J Hepatol 2011; 54: 1161-7.

5. Dell'Era A, Sotela C, Cubero J, et al. Primary prophylaxis of variceal bleeding in cirrhotic patients: a cohort study. Dig Liver Dis 2008; 40: 936-43.

6. Huang $\mathrm{YH}$, Yeh $\mathrm{HZ}$, Chen $\mathrm{GH}$, et al. Endoscopy treatment of bleeding gastric varices by Histoacryl injection. Gastrointest Endosc 2000; 52: 160-7.

7. Gonzalez A, Augustin S, Dot J, et al. Adding banding ligation is effective as rescue therapy to prevent variceal rebleeding in haemodynamic non-responders to pharmacological therapy. Dig Liver Dis 2012; 44: 55-60.

8. Stiegmann GV. Evolution of endoscopic therapy for esophageal varices. Surg Endosc 2006; 20: 467-70.

9. de Franchis R. Revising consensus in portal hypertension: report of the Baveno $V$ consensus workshop on methodology of diagnosis and therapy in portal hypertension. J Hepatol 2010; 53: 762-8.

10. Cipolletta L, Zambelli A, Bianco MA, et al. Acrylate glue injection for the emergency treatment of bleeding esophageal varices: a prospective clinical study. Dig Liver Dis 2008; 40S: S156.

11. Safranek J, Geiger J, Vesely V, et al. Esophageal stents for less invasive treatment of mediastinitis. Videosurgery Miniinv 2014; 9: 1-5.

12. Kurek K, Baniukiewicz A, Świdnicka-Siergiejko A, et al. Application of cyanoacrylate in difficult-to-arrest acute non-variceal gastrointestinal bleeding. Videosurgery Miniinv 2014; 9: 489-93.

13. Safwat $W$. The use of n-2-butyl cyanoacrylate as a rescue therapy for re-bleeding and uncontrollable bleeding from esophageal varices. Gastrointest Endosc 2009; 69: AB 619.

14. Iwase H, Shimada M, Hirashima N, et al. Long-term endoscopic obliteration with Cyanoacrylate glue for isolated gastric variceal bleeding - a 15-year prospective evaluation. Gastrointest Endosc 2009; 69: AB 621.

15. Seewald S, Ang TL, Imazu H, et al. A standardizet injection technique regiment ensures success and safety of $\mathrm{N}$-butyl-2-cyanoacrylate injection for the treatment of gastric fundal varices. Gastrointest Endosc 2008; 68: 447-54.

16. Wróblewski T, Rowiński O, Pawlak J. Przezskórne przezszyjne wewnatrzwątrobowe zespolenie wrotno-czcze. Pol Przegl Chir 1993; 65: 358-61.

17. Sosada K, Wiewióra M, Piecuch J. Literature review of non-operative management of patients with blunt splenic injury: impact of splenic artery embolization. Videosurgery Miniinv 2014; 9: 309-14.

Received: 16.11 .2015

Accepted: 19.11.2015 